\title{
1 Atrial fibrillation is associated with cognitive decline in \\ 2 stroke-free subjects: The Tromsø Study
}

3 Sweta Tiwari, MPH ${ }^{1}$, Maja-Lisa Løchen, MD, $\mathrm{PhD}^{1}$, Bjarne K. Jacobsen, $\mathrm{PhD}^{1}$, Laila A.

4 Hopstock, MScN, $\mathrm{PhD}^{1,2}$, Audhild Nyrnes, $\mathrm{MD}, \mathrm{PhD}^{3}$, Inger Njølstad, MD, $\mathrm{PhD}^{1}$, Ellisiv B.

5 Mathiesen, $\mathrm{MD}, \mathrm{PhD}^{4,5}$, Kjell A. Arntzen, $\mathrm{MD}, \mathrm{PhD}^{4}$, Jocasta Ball, $\mathrm{PhD}^{6}$, Simon Stewart, $\mathrm{PhD}^{7}$,

6 Tom Wilsgaard, $\mathrm{PhD}^{1}$, Henrik Schirmer, $\mathrm{MD}, \mathrm{PhD}^{4,8}$

7

$8{ }^{1}$ Department of Community Medicine, UiT The Arctic University of Norway, Troms $\varnothing$, Norway

$9{ }^{2}$ Department of Health and Care Sciences, UiT The Arctic University of Norway, Troms $\emptyset$,

10 Norway

$11{ }^{3}$ Department of Geriatric Medicine, University Hospital of North Norway, Troms $\varnothing$, Norway

$12{ }^{4}$ Department of Clinical Medicine, UiT The Arctic University of Norway, Troms $\varnothing$, Norway

$13{ }^{5}$ Department of Neurology and Neurophysiology, University Hospital of North Norway, Troms $\varnothing$,

14 Norway

$15{ }^{6}$ Pre-Clinical Disease and Prevention, Baker Heart and Diabetes Institute, Melbourne, Australia

$16{ }^{7}$ Mary MacKillop Institute for Health Research, Australian Catholic University, Melbourne,

17 Australia 
3 Corresponding author: Sweta Tiwari, Department of Community Medicine, UiT The Arctic

4 University of Norway, N-9037 Troms $\varnothing$, Norway, E-mail: sweta.tiwari@uit.no Telephone: +47

577645352

6 Running title: Atrial fibrillation and cognitive decline

7 Keywords: atrial fibrillation, cognitive decline, longitudinal study

8 Word count: 3498

9 Conflicts of interest: Dr. Schirmer reports personal fees from Astra Zeneca, other authors

10 declare no conflicts of interest. 


\section{Abstract}

2 Background: Previous studies have shown associations between atrial fibrillation (AF) and

3 cognitive decline. We investigated this association in a prospective population study, focusing on

4 whether stroke risk factors modulated this association in stroke-free women and men.

5 Methods: We included 4983 participants (57\% women) from the $5^{\text {th }}$ survey of the Troms $\varnothing$ Study

6 (Troms $\varnothing 5,2001$ ), of whom 2491 also participated in $6^{\text {th }}$ survey (Troms $\left.\varnothing 6,2007-08\right)$.

7 Information about age, education, blood pressure, body mass index, lipids, smoking, coffee

8 consumption, physical activity, depression, coronary and valvular heart disease, heart failure and

9 diabetes was obtained at baseline. AF status was based on hospital records. The outcome was

10 change in cognitive score from Troms $\varnothing 5$ to Troms $\varnothing 6$, measured by the verbal memory test, the

11 digit-symbol coding test and the tapping test.

12 Results: Mean age at baseline was 65.4 years. The mean reduction in the tapping test scores was

13 significantly larger in participants with AF (5.3 taps/10 sec, 95\% confidence interval (CI) 3.9,

14 6.7) compared to those without $\mathrm{AF}$ (3.8 taps/10 sec, $95 \%$ CI 3.5, 4.1). These estimates were

15 unchanged when adjusted for other risk factors and were similar for both sexes. AF was not

16 associated with change in the digit-symbol coding or the verbal memory tests.

17 Conclusion: AF in stroke-free participants was independently associated with cognitive decline 18 as measured with the tapping test. 


\section{Introduction}

2 Atrial fibrillation (AF) is a common arrhythmia, associated with increased mortality and

3 morbidity [1]. There is a decrease in the incidence and mortality of cardiovascular diseases

4 (CVD), however AF prevalence does not follow this trend [2]. The number of AF patients is

5 expected to rise due to better detection of silent AF, increasing age and conditions predisposing

6 to $\mathrm{AF}$ [1]. The AF incidence increases with age and is higher in men [3].

7

8 AF increases the risk of stroke and heart failure. A growing body of evidence suggests AF as a

9 risk factor for cognitive decline and dementia [2]. Several cross-sectional studies showed a

10 positive association between $\mathrm{AF}$ and cognitive impairment [4, 5]. A meta-analysis including four

11 cross-sectional and six prospective studies confirmed this association independent of stroke

12 history [6].

14 The $\mathrm{CHA}_{2} \mathrm{DS}_{2}$-VASc score estimates stroke risk in non-anticoagulated AF patients by combining

15 risk factors for stroke. Based on data from the Tromsø Study, we have previously shown that

16 adding left atrial (LA) size to an elevated $\mathrm{CHA}_{2} \mathrm{DS}_{2}$-VASc score provided additional

17 stratification of stroke risk [7]. In this study, we aimed to investigate the association between AF

18 and cognitive function in a population study with six years of follow-up of stroke-free women

19 and men. Furthermore, we investigated whether known stroke risk factors modulate this

20 association. 


\section{Methods}

\section{Study population}

3 The Tromsø Study is a prospective cohort study with a mainly Caucasian population [8] and

4 includes seven surveys (1974 to 2016) referred to as Tromsø 1-7. Total birth cohorts and random

5 population samples are invited, with 45473 individuals having participated in one or more

6 survey. This study population constitutes subjects attending Troms $\emptyset 5$ and 6 , as cognitive testing

7 started in Troms $\varnothing 5$.

8

9 Eligible were participants in Troms $\varnothing 5$ in 2001 (cross-sectional analysis) and in both Troms $\varnothing 5$

10 and Troms $\varnothing 6$ in 2007-08 (longitudinal analysis). In Troms $\varnothing$ 5, 8130 participants aged 30-89

11 years attended [8]. After exclusions, 4983 participants (57\% women) were included for the cross-

12 sectional analyses (Figure 1). Of these, 3409 subjects participated in Troms $\emptyset 6$ and after

13 exclusion, 2491 participants were included for the longitudinal analysis (Figure 1). The Troms $\emptyset$

14 Study has been approved by the Regional Committee for Medical and Health Research Ethics

15 and the Norwegian Data Protection Authority. All participants have given written informed

16 consent.

17

\section{Baseline characteristics}

19 Questionnaire data were used to define the covariates diabetes (yes/no), antihypertensive

20 treatment (current/previous/never), smoking (current/previous/never), education, physical

21 activity, depression and prevalent myocardial infarction (yes/no). Education was categorized as

22 primary/secondary school, upper secondary school, college/university $<4$ years and

23 college/university $\geq 4$ years. Physical activity was categorized as active or sedentary. Body mass 
1 index (BMI) was calculated as weight $/$ height $^{2}\left(\mathrm{~kg} / \mathrm{m}^{2}\right)$ and body surface area (BSA) was

2 calculated by Du Bois formula $\left(\left(\right.\right.$ Weight $^{0.425} \times$ Height $\left.\left.^{0.725}\right) \times 0.007184\right)$. Blood pressure was

3 automatically recorded three times with one-minute intervals after two minutes resting (Dinamap

4 Vital Signs Monitor 1846, Criticon), and the mean from the last two readings was used.

5 Hypertension was defined as systolic blood pressure $\geq 140 \mathrm{mmHg}$, diastolic blood pressure $\geq 90$

$6 \mathrm{mmHg}$ or antihypertensive treatment.

\section{Echocardiography}

9 Echocardiography was performed by two cardiologists on a random subsample $(n=1722)$ in

10 Troms $\varnothing 5$ [7], using the standard apical and parasternal long and short axis views. Standard 2D-

11 guided M-mode registrations of anteroposterior LA size, internal dimensions of the LV and wall-

12 thickness of the septum and posterior wall were made. Heart failure was defined as ventricular

13 ejection fraction $<50 \%$.

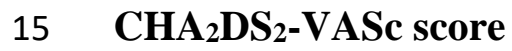

16 We calculated $\mathrm{CHA}_{2} \mathrm{DS}_{2}$-VASc score as follows; age $(65-74:+1, \geq 75:+2)$, sex $($ female $\geq 65:+1)$,

17 history of congestive heart failure (+1), hypertension (+1), stroke/ transient ischemic attack /

18 thromboembolism (+2), vascular disease $(+1)$ and diabetes mellitus $(+1)[7,9]$. Few subjects

$19(1 \%)$ had heart failure in the echocardiography subsample. Thus, subjects without

20 echocardiography were categorized as without heart failure.

\section{Cognitive testing}

23 We assessed cognitive function by three standardized tests, chosen because of their ability to 24 detect early cognitive decline and their feasibility in screenings [10]. 
1 The twelve-word memory test tests short time verbal memory. Twelve nouns were shown written

2 on a board and pronounced one at a time with five-second intervals [10]. The participants had

3 two minutes to recall the words. One point was given for each word correctly recalled, giving the

$4 \quad$ range from 0 to 12 points.

5

6 Digit-symbol coding test, a part of the Wechsler adult intelligence scale, was used to examine

7 psychomotor speed, attention, and mental flexibility [10]. Rows containing small blank squares

8 were each paired with a randomly assigned number from one to nine. Above these rows, a printed

9 key paired each number with a different nonsense symbol. Following a practice trial, the subjects

10 filled in as many as possible of the blank spaces with the corresponding symbol over 90 seconds.

12 Tapping test is a test mainly of psychomotor tempo. The subjects were instructed to tap as many

13 times as possible for ten seconds with their index finger on a computer, which registered the

14 number of taps. The task was repeated four times on both hands. The mean number of taps from

15 the last three tests were used in the analyses [10]. Low test scores are defined as < 4 for the verbal

16 memory test, $<12$ for the digit-symbol coding test and $<23$ for the tapping test [11].

\section{Atrial fibrillation}

19 AF was documented by electrocardiogram based on a search of the diagnosis registry of the

20 University Hospital of North Norway (outpatient clinic included) [12] (ICD-9 codes 427.0-

21427.99 and ICD-10 codes I47 and I48). For participants with a diagnosis of cerebrovascular or

22 cardiovascular event without an arrhythmia diagnosis, text searches with 'atrial fibrillation' were

23 performed. An independent endpoint committee adjudicated the events. All AF types were 
merged. Participants with AF occurring only during an acute myocardial infarction, cardiac surgery, or in the last seven days of life, were not classified with AF.

\section{Categorization of left atrial size}

5 LA size was indexed by BSA and categorized as normal $\left(<2.2 \mathrm{~cm} / \mathrm{m}^{2}\right)$, moderately $(2.2-2.79$

$\left.6 \mathrm{~cm} / \mathrm{m}^{2}\right)$ and severely enlarged $\left(\geq 2.8 \mathrm{~cm} / \mathrm{m}^{2}\right)$ LA.

\section{Statistical analysis}

9 We present sex stratified characteristics as means and standard deviation for continuous variables

10 and proportions for categorical variables. Differences between groups were assessed by t-test and

$11 \chi^{2}$ test. Mean cognitive score in Troms $\varnothing 5$ according to age groups, AF status and LA size

12 adjusted for age, sex and education was estimated. Mean change in test scores from Troms $\emptyset 5$ to

136 were estimated with multivariable linear regression, adjusted for baseline score, age, sex and

14 education (model 1), and with further adjustments for total/HDL cholesterol ratio, BMI,

15 hypertension and smoking (model 2). The echocardiography sub-sample was analyzed separately

16 (model 3) using the same adjustments as in model 2 and with further adjustment for LA size

17 (model 4). We confirmed the model assumptions by graphical inspection of residuals. We

18 tested for interactions between age and AF, and sex and AF, for change in cognitive score, and

19 for $\mathrm{CHA}_{2} \mathrm{DS}_{2}-\mathrm{VASc}$ score, $\mathrm{AF}$ and LA with sex and education for each cognitive test. Sex

20 combined results are presented as sex-specific results were similar and no sex interaction was

21 found. A two-sided p-value $<0.05$ was considered statistically significant. Statistical analysis was

22 performed using STATA V.14 (Stata, College Station, Texas, USA). 


\section{Results}

2 Baseline characteristics are presented in Table 1. The mean age was about 65 years for both

3 sexes. Men had higher educational level, total/HDL cholesterol ratio and were more physically

4 active. There was no sex difference in BMI and diabetes prevalence. Approximately $25 \%$ in both

5 sexes were smokers. Hypertension, myocardial infarction and AF were more prevalent in men,

6 but women had higher $\mathrm{CHA}_{2} \mathrm{DS}_{2}-\mathrm{VASc}$ score and higher prevalence of enlarged LA.

7

8 As the cognitive tests all had a distribution near normal, adjusted mean cognitive scores in

9 Troms $\emptyset 5$ (all participants and the sub-sample with repeated measurements) and adjusted mean

10 changes in cognitive scores are shown in Table 2. The mean cognitive score was lower among

11 older participants and in those with AF and enlarged LA. The decline in cognitive scores was

12 similarly larger among those of older age, with enlarged LA size (statistically significant for the

13 digit-symbol coding test) and among those with AF (statistically significant for the tapping test).

15 Table 3 shows change in cognitive score over 6 years by AF status. For subjects with AF, decline

16 in cognitive test as measured by the tapping test was significantly $(\mathrm{p}=0.04)$ larger $(-5.3(95 \% \mathrm{CI}$ :

$17-6.7,-3.9))$ compared to those without AF (-3.8 (95 \% CI: $-4.1,-3.5))$, and the same trend was seen

18 for the digit-symbol coding test. Adjustment for other risk factors changed the estimates

19 marginally. The log-likelihood ratio $\chi 2$ statistics for tapping test was not significant $(\mathrm{p}=0.16)$

20 when comparing models with and without risk factors. Adding depression and activity as co-

21 variates in model 2 did not change the result, but reduced the number of participants due to

22 missing values. When restricting the material to subjects with echocardiography (Model 3 and 4),

23 the adjustment for LA size had no effect. 
1 We also performed the analysis including $\mathrm{CHA}_{2} \mathrm{DS}_{2}-\mathrm{VASc}$ score together with AF in model 2

2 instead of age and sex. Baseline score and education were kept in the model. Furthermore, we re-

3 analyzed the data by substituting $\mathrm{CHA}_{2} \mathrm{DS}_{2}$-VASc score with its individual components. The

4 change in cognitive test scores associated with $\mathrm{AF}$ was similar and the main contributing

5 components of the score were age and sex. In addition, we performed age and sex-stratified

6 analyses, but only presented the non-stratified result due to lower statistical power.

\section{Discussion}

8 In this prospective population-based study of stroke-free subjects, we found that AF was

9 significantly associated with $40 \%$ greater cognitive decline as measured by the tapping test. To

10 our knowledge, no other population studies have examined the association between $\mathrm{AF}$ and

11 cognitive decline using repeated standardized cognitive tests.

13 Our study confirms other studies in stroke-free subjects [13-15]. These studies mainly used the

14 Mini-Mental State Examination (MMSE) or other established diagnostic criteria for evaluating

15 cognitive function. The large prospective multi-national ONTARGET and TRANSCEND trials,

16 found that participants with AF had a $14 \%$ increased risk of cognitive decline, defined as a

17 decrease of 3 or more points in the MMSE test [16]. Similar results were found in studies among

18 men $[17,18]$. Another longitudinal study found no association between $\mathrm{AF}$ and cognitive decline

19 [19]. ARIC (Atherosclerosis Risk in Communities) Study found an association between cognitive 20 function and persistent AF [20]. 
1 Adjusting the association between $\mathrm{AF}$ and change in cognitive score for established risk factors

2 did not change the conclusions. Additionally, when including the $\mathrm{CHA}_{2} \mathrm{DS}_{2}$-VASc score, we

3 found that age and sex were the main contributing components. One study including subjects

4 with and without stroke found $\mathrm{CHA}_{2} \mathrm{DS}_{2}-\mathrm{VASc}$ score as a significant predictor of dementia

5 among AF patients [21]. Our study was among stroke-free participants and few had heart failure,

6 vascular disease or diabetes, which might explain the result. Previously we found an increased

7 stroke risk associated with LA enlargement, possibly due to increased risk of emboli, but adding

8 LA size to our model did not affect the estimates. As only a subsample had measurements of LA

9 size, the power to detect effects was low.

11 The association between $\mathrm{AF}$ and cognitive decline depends on the characteristics of the $\mathrm{AF}$

12 population. The association may not be directly related to AF, but could be due to an aging

13 cohort with comorbidities. Several mechanisms may explain the association between AF and

14 cognitive impairment, such as silent cerebral infarct, microemboli, microbleedings and cerebral

15 hypoperfusion [22-26].

17 Finger tapping is an important test of cognitive function, as reduced motor speed is a sensitive

18 marker of motor and cognitive cerebral dysfunction such as reduced manual dexterity,

19 coordination and global performance [27]. One study found that motor slowing as indicated by

20 finger tapping speed precede cognitive impairment [28]. Others found that stroke subjects

21 compared to stroke-free subjects were best discriminated by impaired motor speed with non-

22 dominant hand [29]. Finger tapping frequency was found to independently predict psychomotor

23 slowing following stroke [30]. 


\section{Strengths}

2 Our study was performed in a large population of both sexes, with a high attendance rate, long

3 follow-up and repeated assessments of sensitive cognitive tests that are feasible in a population

4 screening [10]. Hospital data concerning stroke and AF underwent thorough case validation.

\section{$5 \quad$ Limitations}

6 Selection bias may occur because of lower participation rate among individuals with dementia.

7 Participants with repeated cognitive testing were younger with better risk factor profile than those

8 who were lost to follow-up. Though invited, institutionalized persons were probably not able to

9 attend the $6^{\text {th }}$ survey or to complete the questionnaires. Selection of subjects during data

10 collection might have occurred, as 561 more participants completed the tapping test than the

11 digit-symbol coding test in Troms $\emptyset 5$ and it is likely that the proportion of subjects with cognitive

12 impairment was higher among those who did not complete all tests. Information of AF and stroke

13 was collected through linkage to the hospital diagnosis registry and the National Causes of Death

14 Registry at Statistics Norway; this could have led to underestimation of non-fatal strokes and

15 undiagnosed AF, if subjects were not hospitalized.

\section{Conclusions}

18 AF was independently associated with cognitive decline as measured with the tapping test in both 19 sexes of stroke free subjects. Screening of AF patients for cognitive decline is warranted.

21 Conflict of Interest: None 


\section{References}

2 1. Kirchhof P, Benussi S, Kotecha D, et al. 2016 ESC Guidelines for the management of

3 atrial fibrillation developed in collaboration with EACTS. Eur Heart J 2016; 37: 2893-2962.

4 2. Alonso A, Arenas de Larriva AP. Atrial Fibrillation, Cognitive Decline And Dementia.

5 Eur Cardiol 2016; 11: 49-53.

6 3. Heeringa J, van der Kuip DA, Hofman A, et al. Prevalence, incidence and lifetime risk of

7 atrial fibrillation: the Rotterdam study. Eur Heart J 2006; 27: 949-953.

8 4. Knecht S, Oelschlager C, Duning T, et al. Atrial fibrillation in stroke-free patients is

9 associated with memory impairment and hippocampal atrophy. Eur Heart J 2008; 29: 2125-2132.

10 5. Ball J, Carrington MJ, Stewart S, SAFETY investigators. Mild cognitive impairment in

11 high-risk patients with chronic atrial fibrillation: a forgotten component of clinical management?

12 Heart 2013; 99: 542-547.

13 6. Kalantarian S, Stern TA, Mansour M, Ruskin JN. Cognitive impairment associated with 14 atrial fibrillation: a meta-analysis. Ann Intern Med 2013; 158: 338-346.

$157 . \quad$ Tiwari S, Løchen ML, Jacobsen BK, et al. $\mathrm{CHA}_{2} \mathrm{DS}_{2}$-VASc score, left atrial size and 16 atrial fibrillation as stroke risk factors in the Troms $\varnothing$ Study. Open Heart 2016; 3: e000439.

17 8. Jacobsen BK, Eggen AE, Mathiesen EB, Wilsgaard T, Njølstad I. Cohort profile: the 18 Tromsø Study. Int J Epidemiol 2012; 41: 961-967.

19 9. Iqbal A, Rodriguez F, Schirmer H. Antiplatelet Therapy During PCI for Patients with 20 Stable Angina and Atrial Fibrillation. Curr Cardiol Rep 2015; 17: 615.

21 10. Arntzen KA, Schirmer H, Wilsgaard T, Mathiesen EB. Impact of cardiovascular risk 22 factors on cognitive function: the Tromsø study. Eur J Neurol 2011; 18: 737-743. 
1 11. Rogne S, Vangberg T, Eldevik P, Wikran G, Mathiesen EB, Schirmer H. Mild cognitive

2 impairment, risk factors and magnetic resonance volumetry: role of probable Alzheimer's disease

3 in the family. Dement Geriatr Cogn Disord 2013; 36: 87-98.

$4 \quad$ 12. Nyrnes A, Mathiesen EB, Njølstad I, Wilsgaard T, Løchen ML. Palpitations are

5 predictive of future atrial fibrillation. An 11-year follow-up of 22,815 men and women: the

6 Troms $\varnothing$ Study. Eur J Prev Cardiol 2013; 20: 729-736.

7 13. O'Connell JE, Gray CS, French JM, Robertson IH. Atrial fibrillation and cognitive

8 function: case-control study. J Neurol Neurosurg Psychiatry 1998; 65: 386-389.

9 14. Rozzini R, Sabatini T, Trabucchi M. Chronic atrial fibrillation and low cognitive function.

$10 \quad$ Stroke 1999; 30: 190-191.

11 15. Thacker EL, McKnight B, Psaty BM, et al. Atrial fibrillation and cognitive decline: a

12 longitudinal cohort study. Neurology 2013; 81: 119-125.

13 16. Marzona I, O'Donnell M, Teo K, et al. Increased risk of cognitive and functional decline

14 in patients with atrial fibrillation: results of the ONTARGET and TRANSCEND studies. CMAJ

$15 \quad 2012 ; 184:$ E329-336.

16 17. Elias MF, Sullivan LM, Elias PK, et al. Atrial fibrillation is associated with lower

17 cognitive performance in the Framingham offspring men. J Stroke Cerebrovasc Dis 2006; 15 :

$18 \quad 214-222$.

19 18. Kilander L, Andren B, Nyman H, Lind L, Boberg M, Lithell H. Atrial fibrillation is an

20 independent determinant of low cognitive function: a cross-sectional study in elderly men. Stroke

21 1998; 29: 1816-1820.

22 19. Park H, Hildreth A, Thomson R, O'Connell J. Non-valvular atrial fibrillation and

23 cognitive decline: a longitudinal cohort study. Age Ageing 2007; 36: 157-163. 
1 20. Chen LY, Agarwal SK, Norby FL, et al. Persistent but not Paroxysmal Atrial Fibrillation

2 Is Independently Associated With Lower Cognitive Function: ARIC Study. J Am Coll Cardiol

$3 \quad 2016 ; 67:$ 1379-1380.

4 21. Liao JN, Chao TF, Liu CJ, et al. Risk and prediction of dementia in patients with atrial

5 fibrillation--a nationwide population-based cohort study. Int J Cardiol 2015; 199: 25-30.

6 22. de la Torre JC. Cardiovascular risk factors promote brain hypoperfusion leading to

$7 \quad$ cognitive decline and dementia. Cardiovasc Psychiatry Neurol 2012; 2012: 367516.

8 23. Lei C, Lin S, Tao W, Hao Z, Liu M, Wu B. Association between cerebral microbleeds

9 and cognitive function: a systematic review. J Neurol Neurosurg Psychiatry 2013; 84: 693-697.

10 24. Gross AF, Stern TA. The cognitive impact of atrial fibrillation. Prim Care Companion

11 CNS Disord 2013; 15.

12 25. Gaita F, Corsinovi L, Anselmino M, et al. Prevalence of silent cerebral ischemia in

13 paroxysmal and persistent atrial fibrillation and correlation with cognitive function. J Am Coll

14 Cardiol 2013; 62: 1990-1997.

15 26. Chen LY, Lopez FL, Gottesman RF, et al. Atrial Fibrillation and Cognitive Decline-The

16 Role of Subclinical Cerebral Infarcts: The ARIC Study. Stroke 2014; 45: 2568-2574.

17 27. Desrosiers J, Bourbonnais D, Bravo G, Roy PM, Guay M. Performance of the 'unaffected'

18 upper extremity of elderly stroke patients. Stroke 1996; 27: 1564-1570.

19 28. Camicioli R, Howieson D, Oken B, Sexton G, Kaye J. Motor slowing precedes cognitive

20 impairment in the oldest old. Neurology 1998; 50: 1496-1498.

21 29. Engstad T, Almkvist O, Viitanen M, Arnesen E. Impaired motor speed, visuospatial

22 episodic memory and verbal fluency characterize cognition in long-term stroke survivors: the

23 Troms $\varnothing$ Study. Neuroepidemiology 2003; 22: 326-331. 
1 30. Godefroy O, Spagnolo S, Roussel M, Boucart M. Stroke and Action Slowing:

2 Mechanisms, Determinants and Prognosis Value. Cerebrovasc Dis 2010; 29: 508-514.

3

4

5

6

7

8

9

10

11

12

13

14

15

16

17

18 
2 Figure 1 Study population, The Troms $\varnothing$ Study 2001-2008

5 Table Legend

6

7 Table 1: Unadjusted baseline characteristics of the participants by sex. The Troms $\varnothing$ Study:

8 Tromsø 5 (2001)

9

10 Table 2: Mean cognitive tests scores (95\% confidence intervals (CI)) in Troms $\emptyset 5$ and mean

11 change in test scores between Troms $\varnothing 5$ and Troms $\emptyset 6$ by age, atrial fibrillation status and left

12 atrial size. The Tromsø Study

13

14 Table 3 Mean (95\% confidence interval (CI)) change in cognitive test scores over 6 years

15 according to atrial fibrillation (AF) status. The Troms $\emptyset$ Study

16

17 


\section{Exclusion}

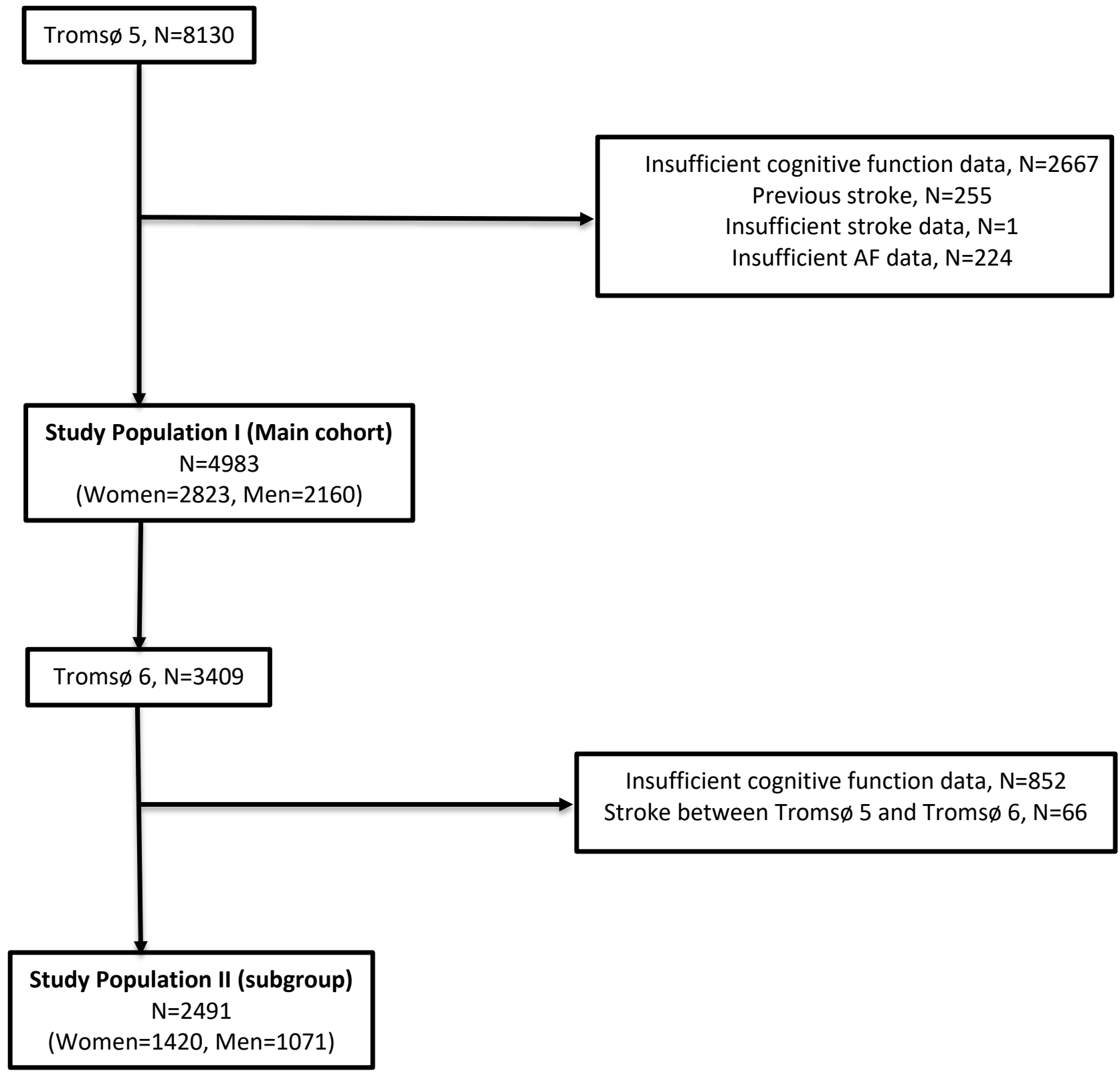

Figure 1 Study population, The Troms $\varnothing$ Study 2001-2008 
Table 1: Unadjusted baseline characteristics of the participants by sex. The Troms $\emptyset$ Study:

Tromsø 5 (2001)

\begin{tabular}{|c|c|c|c|}
\hline Baseline characteristics & Women $(n=2823)$ & $\operatorname{Men}(n=2160)$ & p-value for sex-difference \\
\hline Age (years) & $65.3(9.8)$ & $65.6(9.3)$ & 0.16 \\
\hline Education, \% (n) & & & $<0.0001$ \\
\hline Primary and secondary school & $59.9(1600)$ & $51.8(1069)$ & \\
\hline Upper secondary/high school & $22.3(594)$ & $26.3(543)$ & \\
\hline College/university $<4$ years & $9.3(247)$ & $11.9(245)$ & \\
\hline College/university $\geq$ 4years & $8.6(229)$ & $10.1(208)$ & \\
\hline Systolic blood pressure $(\mathrm{mmHg})$ & $143.0(23.0)$ & $143.2(20.5)$ & 0.83 \\
\hline Diastolic blood pressure $(\mathrm{mmHg})$ & $80.6(13.0)$ & $82.6(11.9)$ & $<0.0001$ \\
\hline Body mass index $\left(\mathrm{kg} / \mathrm{m}^{2}\right)$ & $26.8(4.6)$ & $26.8(3.5)$ & 0.66 \\
\hline Total cholesterol (mmol/l) & $6.51(1.18)$ & $6.09(1.12)$ & $<0.0001$ \\
\hline HDL cholesterol (mmol/l) & $1.59(0.40)$ & $1.36(0.37)$ & $<0.0001$ \\
\hline Total/HDL- cholesterol ratio & $4.31(1.25)$ & $4.78(1.42)$ & $<0.0001$ \\
\hline Smoking, \% (n) & & & $<0.0001$ \\
\hline No smoking & $48.7(1375)$ & $23.1(499)$ & \\
\hline Previous smoking & $27.1(765)$ & $52.4(1131)$ & \\
\hline Current smoking & $24.2(683)$ & $24.5(530)$ & \\
\hline Physically active, \% (n) & $73.2(1853)$ & $80.9(1674)$ & $<0.0001$ \\
\hline Hypertension, \% (n) & $60.4(1705)$ & $63.3(1368)$ & 0.04 \\
\hline $\begin{array}{l}\text { Current antihypertensive treatment, \% } \\
\text { (n) }\end{array}$ & $23.4(641)$ & $23.6(498)$ & 0.97 \\
\hline Depression, \% (n) & $3.8(89)$ & $1.4(28)$ & $<0.0001$ \\
\hline $\mathrm{CHA}_{2} \mathrm{DS}_{2}-$ VASc score, $\%(\mathrm{n})^{\mathrm{a}}$ & & & $<0.0001$ \\
\hline 0 & $24.1(680)$ & $17.7(382)$ & \\
\hline 1 & $19.3(545)$ & $31.4(678)$ & \\
\hline 2 & $12.0(339)$ & $31.3(675)$ & \\
\hline 3 & $27.5(777)$ & $16.1(347)$ & \\
\hline$\geq 4$ & $17.1(482)$ & $3.6(78)$ & \\
\hline Coronary heart disease, $\%(\mathrm{n})$ & $3.8(104)$ & $11.8(253)$ & $<0.0001$ \\
\hline Diabetes, \% (n) & $3.9(107)$ & $4.5(97)$ & 0.27 \\
\hline Atrial fibrillation, \% (n) & $2.9(83)$ & $4.9(106)$ & $<0.0001$ \\
\hline $\begin{array}{l}\text { Subsample with echocardiography } \\
\text { data }\end{array}$ & Women $(\mathrm{n}=\mathbf{8 8 5})$ & Men $(n=837)$ & \\
\hline Left atrial size, \% (n) & & & $<0.0001$ \\
\hline$<2.2 \mathrm{~cm} / \mathrm{m}^{2}$ & $43.5(385)$ & $59.0(494)$ & \\
\hline $2.2-2.79 \mathrm{~cm} / \mathrm{m}^{2}$ & $52.1(461)$ & $37.5(314)$ & \\
\hline$\geq 2.8 \mathrm{~cm} / \mathrm{m}^{2}$ & $4.4(39)$ & $3.5(29)$ & \\
\hline
\end{tabular}

Number in the table referred as mean values (standard deviation) or \% (number of subjects)

${ }^{\mathrm{a}} \mathrm{CHA}_{2} \mathrm{DS}_{2}$-VASc score: age $(65-74:+1, \geq 75:+2)$, sex (female $\left.\geq 65:+1\right)$, history of congestive heart failure $(+1)$, hypertension $(+1)$, vascular disease $(+1)$ and diabetes mellitus $(+1)$ 
Table 2: Mean cognitive tests scores (95\% confidence intervals (CI)) in Troms $\emptyset 5$ and mean change in test scores between Troms $\varnothing 5$ and Troms $\emptyset 6$ by age, atrial fibrillation status and left atrial size. The Troms $\emptyset$ Study

\begin{tabular}{|c|c|c|c|c|c|c|}
\hline & \multicolumn{4}{|l|}{ Tromsø $5(2001)^{a}$} & \multirow{2}{*}{\multicolumn{2}{|c|}{$\begin{array}{l}\text { Change in test scores from } \\
\text { Tromsø } 5 \text { to Tromsø } 6(95 \% \\
\text { CI })^{\mathrm{b}}(\mathrm{n}=2491)\end{array}$}} \\
\hline & \multicolumn{2}{|l|}{$\begin{array}{l}\text { All participants } \\
(n=4983)\end{array}$} & \multicolumn{2}{|c|}{$\begin{array}{l}\text { Sub-sample with repeat } \\
\text { measurement }(n=2491)\end{array}$} & & \\
\hline & Mean (CI) & p-value & Mean (CI) & p-value & Mean $(\mathrm{CI})$ & p-value \\
\hline \multicolumn{7}{|l|}{ Verbal memory test $^{\mathrm{e}}$} \\
\hline Age groups (years) & & $<0.0001^{\mathrm{c}}$ & & $<0.0001^{\mathrm{c}}$ & & $<0.0001^{\mathrm{c}}$ \\
\hline$<65$ & $6.9(6.8,7.0)$ & & $7.1(7.0,7.2)$ & & $-0.2(-0.3,-0.1)$ & \\
\hline $65-74$ & $6.1(6.0,6.2)$ & & $6.3(6.2,6.4)$ & & $-0.9(-1.0,-0.8)$ & \\
\hline$\geq 75$ & $5.6(5.5,5.7)$ & & $6.0(5.7,6.3)$ & & $-1.5(-1.7,-1.2)$ & \\
\hline Atrial fibrillation & & 0.08 & & 0.68 & & 0.48 \\
\hline No & $6.4(6.3,6.4)$ & & $6.7(6.6,6.8)$ & & $-0.6(-0.6,-0.5)$ & \\
\hline Yes & $6.1(5.9,6.4)$ & & $6.6(6.1,7.1)$ & & $-0.4(-0.7,-0.1)$ & \\
\hline Left atrial size $\left(\mathrm{cm} / \mathrm{m}^{2}\right)^{\mathrm{d}}$ & & $0.17^{\mathrm{c}}$ & & $0.22^{\mathrm{c}}$ & & $0.15^{\mathrm{c}}$ \\
\hline$<2.2$ & $6.4(6.2,6.5)$ & & $6.7(6.6,6.9)$ & & $-0.6(-0.7,-0.4)$ & \\
\hline $2.2-2.79$ & $6.2(6.1,6.4)$ & & $6.5(6.3,6.7)$ & & $-0.5(-0.7,-0.3)$ & \\
\hline$\geq 2.8$ & $6.0(5.5,6.5)$ & & $6.3(5.5,7.1)$ & & $-1.3(-2.0,-0.5)$ & \\
\hline \multicolumn{7}{|l|}{ Digit-symbol coding test ${ }^{\mathrm{f}}$} \\
\hline Age groups (years) & & $<0.0001^{\mathrm{c}}$ & & $<0.0001^{\mathrm{c}}$ & & $<0.0001^{\mathrm{c}}$ \\
\hline$<65$ & $37.5(37.0,38.1)$ & & $38.9(38.2,39.6)$ & & $2.6(2.1,3.2)$ & \\
\hline $65-74$ & $28.6(28.0,29.2)$ & & $30.1(29.3,30.9)$ & & $-3.5(-4.1,-2.8)$ & \\
\hline$\geq 75$ & $23.2(22.4,24.1)$ & & $26.4(24.5,28.3)$ & & $-6.1(-7.7,-4.4)$ & \\
\hline Atrial fibrillation & & 0.05 & & 0.15 & & 0.22 \\
\hline No & $31.7(31.3,32.0)$ & & $34.7(34.2,35.1)$ & & $-0.2(-0.6,0.2)$ & \\
\hline Yes & $29.8(27.9,31.7)$ & & $32.1(28.5,35.6)$ & & $-1.3(-2.9,0.4)$ & \\
\hline Left atrial size $\left(\mathrm{cm} / \mathrm{m}^{2}\right)^{\mathrm{d}}$ & & $0.05^{\mathrm{c}}$ & & $0.29^{\mathrm{c}}$ & & $0.01^{\mathrm{c}}$ \\
\hline$<2.2$ & $32.2(31.4,33.0)$ & & $34.9(33.9,36.0)$ & & $0.01(-0.8,0.8)$ & \\
\hline $2.2-2.79$ & $31.0(30.1,31.8)$ & & $33.7(32.5,34.9)$ & & $-1.9(-2.8,-1.0)$ & \\
\hline$\geq 2.8$ & $29.4(26.5,32.2)$ & & $33.3(28.4,38.3)$ & & $-3.4(-7.5,0.8)$ & \\
\hline \multicolumn{7}{|l|}{ Tapping test ${ }^{\mathrm{g}}$} \\
\hline Age groups (years) & & $<0.0001^{\mathrm{c}}$ & & $<0.0001^{\mathrm{c}}$ & & $<0.0001^{\mathrm{c}}$ \\
\hline$<65$ & $54.6(54.2,55.0)$ & & $55.0(54.6,55.5)$ & & $-2.3(-2.7,-1.8)$ & \\
\hline $65-74$ & $50.7(50.3,51.1)$ & & $51.4(50.9,52.0)$ & & $-5.7(-6.2,-5.1)$ & \\
\hline$\geq 75$ & $46.4(45.8,47.0)$ & & $47.6(46.3,48.9)$ & & $-7.8(-9.3,-6.4)$ & \\
\hline Atrial fibrillation & & 0.08 & & 0.99 & & 0.04 \\
\hline No & $51.7(51.5,52.0)$ & & $53.1(52.8,53.5)$ & & $-3.8(-4.1,-3.4)$ & \\
\hline Yes & $50.5(49.2,51.8)$ & & $53.1(50.8,55.4)$ & & $-5.3(-6.7,-3.9)$ & \\
\hline Left atrial size $\left(\mathrm{cm} / \mathrm{m}^{2}\right)^{\mathrm{d}}$ & & $0.12^{\mathrm{c}}$ & & $0.25^{\mathrm{c}}$ & & $0.34^{\mathrm{c}}$ \\
\hline$<2.2$ & $52.0(51.4,52.6)$ & & $53.4(52.6,54.2)$ & & $-3.5(-4.2,-2.8)$ & \\
\hline $2.2-2.79$ & $51.7(51.0,52.3)$ & & $52.9(52.0,53.8)$ & & $-4.0(-4.8,-3.2)$ & \\
\hline$\geq 2.8$ & $49.7(47.5,51.9)$ & & $50.4(46.8,54.1)$ & & $-5.8(-9.3,-2.3)$ & \\
\hline
\end{tabular}

${ }^{\mathrm{a} A d j u s t e d}$ for age, sex and education. ${ }^{\mathrm{b}}$ adjusted for baseline score, age, sex and education

${ }^{c} \mathrm{P}$-value for linear trend ${ }^{\mathrm{d}} \mathrm{Left}$ atrial size: subsample with echocardiography data $(\mathrm{n}=1722)$ in total sample, $(n=875)$ in repeat measurement

eScores are given as the number of correct words recalled (0-12). fScores are given as the number of correct symbols coded (0-96). ${ }^{\mathrm{g}}$ Scores are given as the average number of taps in 10 second 
Table 3 Mean (95\% confidence interval (CI)) change in cognitive test scores over 6 years according to atrial fibrillation (AF) status. The Troms $\varnothing$ Study.

\begin{tabular}{|c|c|c|c|c|c|c|c|c|}
\hline & \multicolumn{8}{|c|}{ Change in test scores } \\
\hline & \multicolumn{2}{|l|}{ Model 1} & \multicolumn{2}{|l|}{ Model 2} & \multicolumn{2}{|l|}{ Model 3} & \multicolumn{2}{|l|}{ Model 4} \\
\hline & Mean (CI) & p-value & Mean (CI) & p-value & Mean (CI) & p-value & Mean (CI) & p-value \\
\hline Verbal memory test & & 0.48 & & 0.41 & & 0.42 & & 0.37 \\
\hline No AF & $-0.6(-0.6,-0.5)$ & & $-0.6(-0.6,-0.5)$ & & $-0.6(-0.7,-0.4)$ & & $-0.6(-0.7,-0.4)$ & \\
\hline $\mathrm{AF}$ & $-0.4(-0.7,-0.1)$ & & $-0.4(-0.7,-0.1)$ & & $-0.4(-0.8,0.1)$ & & $-0.3(-0.8,0.1)$ & \\
\hline Digit-symbol coding test & & 0.22 & & 0.23 & & 0.77 & & 0.89 \\
\hline No AF & $-0.2(-0.6,0.2)$ & & $-0.2(-0.6,0.2)$ & & $-0.2(-0.7,0.4)$ & & $-0.2(-0.7,0.4)$ & \\
\hline $\mathrm{AF}$ & $-1.3(-2.9,0.4)$ & & $-1.1(-2.8,0.5)$ & & $-0.5(-2.7,1.7)$ & & $-0.3(-2.6,1.9)$ & \\
\hline Tapping test & & 0.04 & & 0.04 & & 0.06 & & 0.09 \\
\hline No AF & $-3.8(-4.1,-3.5)$ & & $-3.8(-4.1,-3.5)$ & & $-3.3(-3.8,-2.9)$ & & $-3.3(-3.8,-2.9)$ & \\
\hline $\mathrm{AF}$ & $-5.3(-6.7,-3.9)$ & & $-5.3(-6.8,-3.9)$ & & $-5.2(-7.1,-3.3)$ & & $-5.0(-6.9,-3.1)$ & \\
\hline
\end{tabular}

Participants that have missing values in any one of the adjustment variables were excluded from analysis in all the models

Model 1: adjusted for baseline score, age, sex and educational level.

Model 2: adjusted for baseline score age, sex, educational level, Total/HDL cholesterol ratio, BMI, hypertension, smoking

Model 3: as Model 2 in the sub-sample with echocardiographic data $(n=873)$

Model 4: as Model 2 with LA index added in the sub-sample with echocardiographic data $(n=873)$ 